\title{
Inflation of Unreefed and Reefed Extraction Parachutes
}

\author{
Eric S. Ray ${ }^{1}$ \\ MRI Technologies, Houston, TX, 77058 \\ Jose G. Varela ${ }^{2}$ \\ GeoControl Systems, Inc., Houston, TX, 77058
}

\begin{abstract}
Data from the Orion and several other test programs have been used to reconstruct inflation parameters for $28 \mathrm{ft} D_{0}$ extraction parachutes as well as the parent aircraft pitch response during extraction. The inflation force generated by extraction parachutes is recorded directly during tow tests but is usually inferred from the payload accelerometer during Low Velocity Airdrop Delivery (LVAD) flight test extractions. Inflation parameters are dependent on the type of parent aircraft, number of canopies, and standard vs. high altitude extraction conditions. For standard altitudes, single canopy inflations are modeled as infinite mass, but the non-symmetric inflations in a cluster are modeled as finite mass. High altitude extractions have necessitated reefing the extraction parachutes, which are best modeled as infinite mass for those conditions. Distributions of aircraft pitch profiles and inflation parameters have been generated for use in Monte Carlo simulations of payload extractions.
\end{abstract}

\section{Nomenclature}

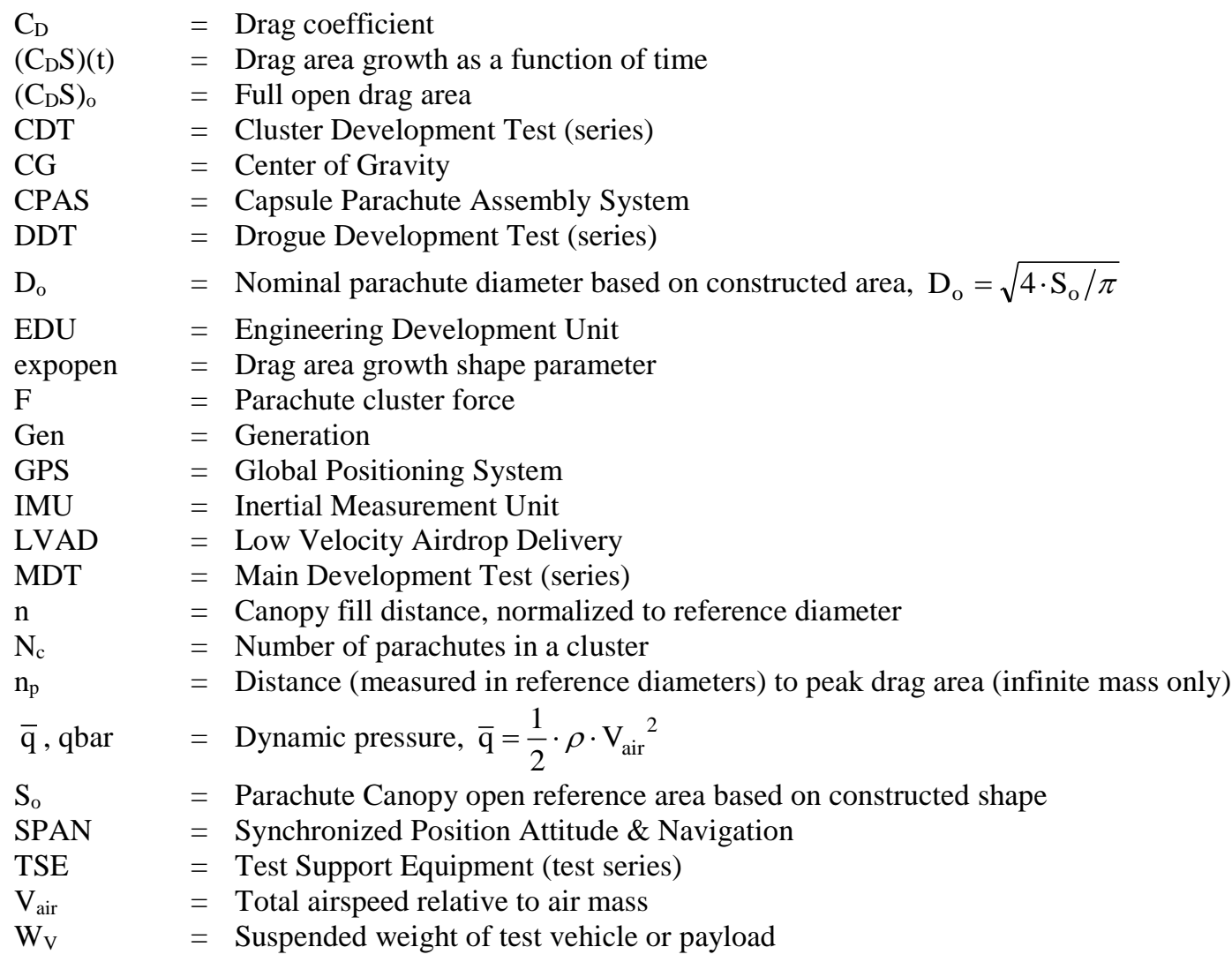

\footnotetext{
${ }^{1}$ Analysis Engineer, Aeroscience and Flight Dynamics, 2224 Bay Area Blvd, Houston, TX, AIAA Member.

${ }^{2}$ Analysis Engineer, Aeroscience and Flight Dynamics, 2224 Bay Area Blvd, Houston, TX, AIAA Sr. Member.
}

American Institute of Aeronautics and Astronautics 


\section{Introduction}

$\mathrm{O}$ RION Capsule Parachute Assembly System (CPAS) flight test techniques have become more complicated with each successive test generation (Gen), as shown in Fig. 1. Each of the Engineering Development Unit (EDU) tests begin with extraction of the mated test vehicle from a parent C-130 or C-17 aircraft. Both the dart-shaped Parachute Compartment Drop Test Vehicle (PCDTV) ${ }^{1}$ and capsule-shaped Parachute Test Vehicle (PTV) ${ }^{2}$ must then separate in mid-air from their respective extraction sleds. Accurate simulations are critical to designing a safe and successful concept of operations.

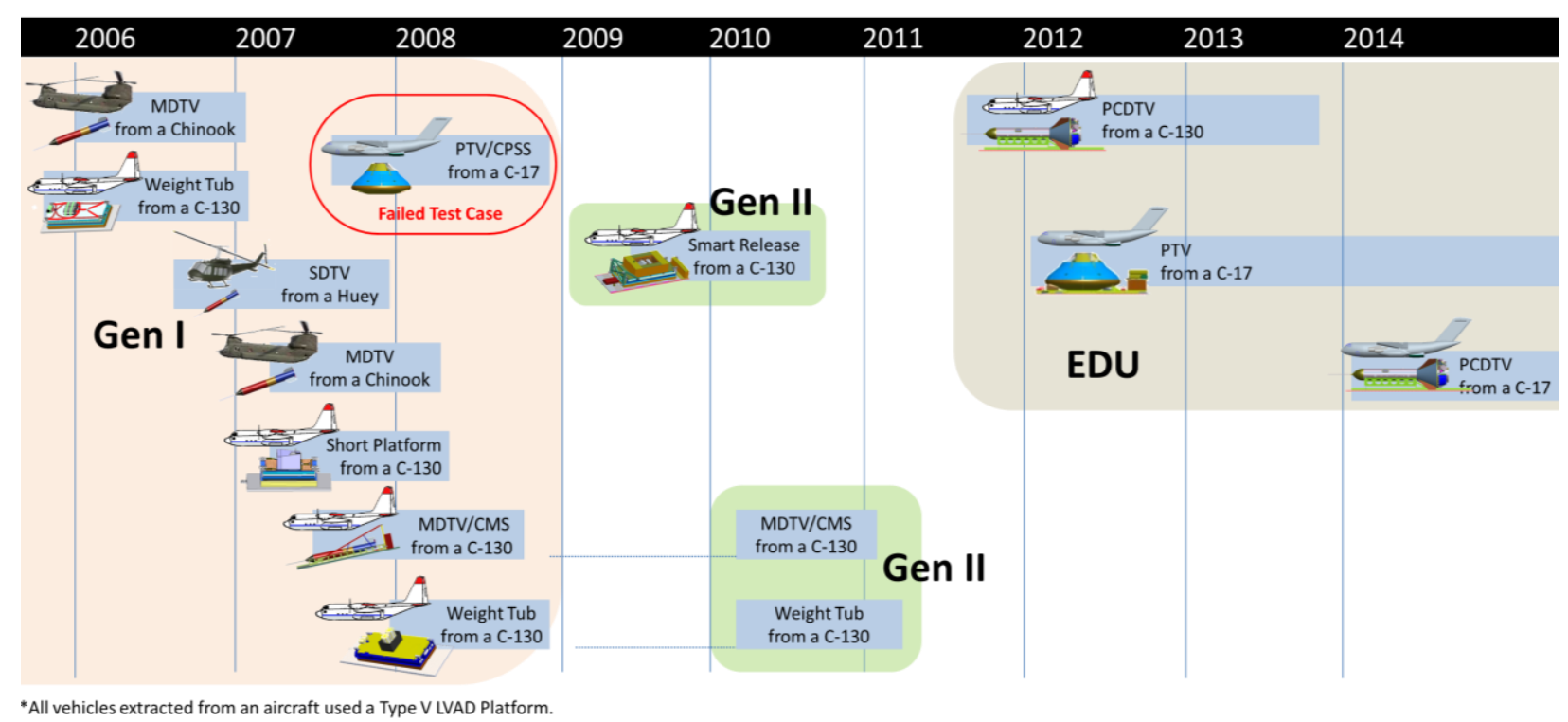

Figure 1. Evolution of CPAS test vehicles and techniques.

Post-flight reconstructions and analyses have advanced extraction simulations during the EDU testing phase. Reconstructions of the Gen I Cluster Development Test $2\left(\right.$ CDT-2) ${ }^{3}$ assisted in validating the MSC/ADAMS tool as applied to the first EDU PTV preflight analysis. This led to a better assessment of the parent aircraft horizontal and vertical state than legacy tools. ${ }^{4}$

Because test article extraction is dominated by the force of the extraction parachute(s), it is critical to model this force accurately to maintain fidelity in simulating the separations ${ }^{5}$ and subsequent flight trajectories. Early data sources, such as AFFDL-TR-66-103, assumed the same $C_{D}$ of 0.55 for all sizes of extraction parachute and conditions. ${ }^{6}$ However, experience has shown that parachute performance is affected by the wake of the aircraft and number of parachutes in a cluster. Flight tests have gradually increased extraction altitude in order to achieve high altitude and airspeed test points in the CPAS parachute deployment envelopes. ${ }^{7}$ This required reefing the extraction parachute in order to control inflation loads.

Aircraft responses, extraction parachute inflation and steady-state parameters have been collected from multiple test types and sources. The data were organized into categories in order to establish probability distributions for highfidelity Monte Carlo simulations. ${ }^{8}$ These distributions are collected in the CPAS Test Technique Memo. ${ }^{9}$

\section{Parent Aircraft Attitude and Reaction}

Improved data measurements in Gen II have greatly increased the understanding of the coupled reactions between the parent aircraft and test article during extraction. Early Global Positioning System (GPS) units would "drop out" during extraction and not re-acquire a solution until late in the flight. The use of the NovAtel SPAN-SE (Synchronized Position Attitude \& Navigation) ${ }^{10}$ GPS coupled with an Inertial Measurement Unit (IMU) ${ }^{11}$ starting in Gen II eliminated the test article dropout problem.

An important consideration in extraction is the pitch plane motion of the parent aircraft and payload. It is well known that the aircraft center of gravity changes as a payload is extracted, creating a reaction pitch rate. Further, the payload will tip upward as its own center of gravity passes over the ramp edge, as illustrated in Fig. 2. For this reason, a second SPAN-SE unit is fixed on the aircraft, allowing for measurement of the relative motion between bodies.

American Institute of Aeronautics and Astronautics 


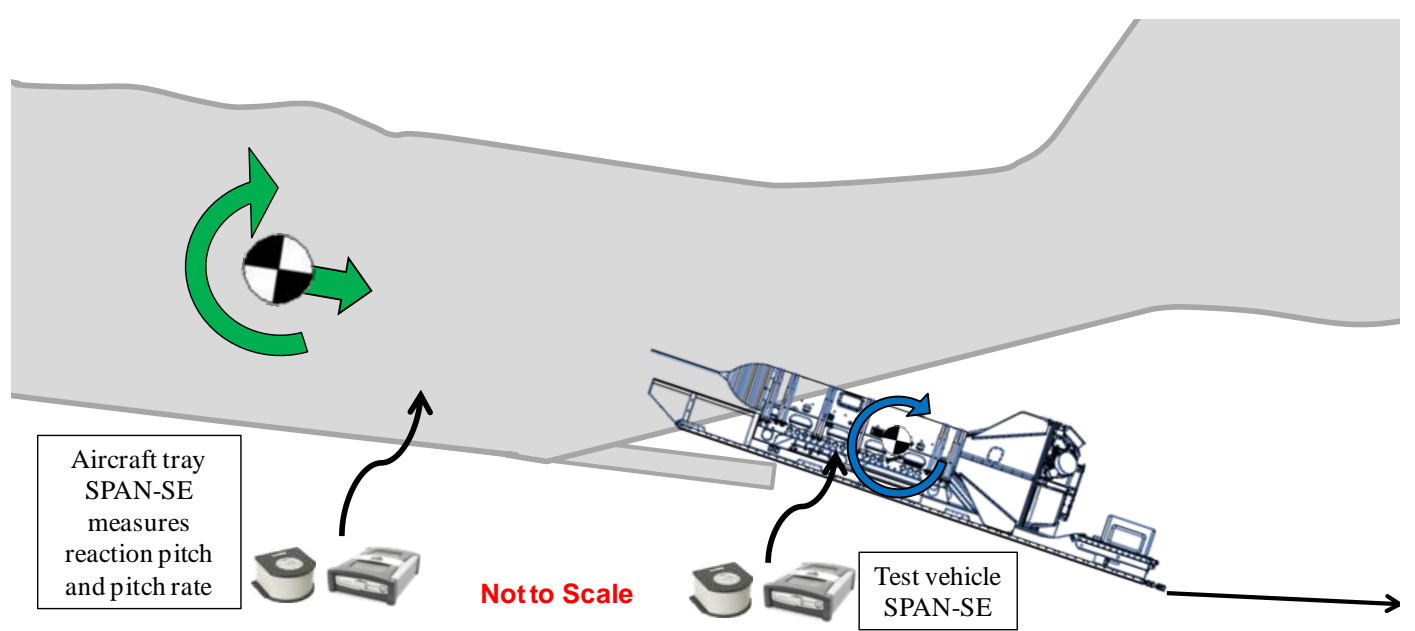

Figure 2. Instrumentation to record parent aircraft reaction during payload extraction.

An example of the pitch rate readings on the $\mathrm{C}-130$ aircraft and test article is plotted in Fig. 3. Aircraft pitch data are sampled (red) and recorded in a look-up table for use in simulations.

The pitch rate data from seven flights are plotted relative to first motion (FM) in Fig. 4. For Monte Carlo analysis, the look-up file from CDT-3-1 is scaled within certain limits in order to encompass most of the test experience.

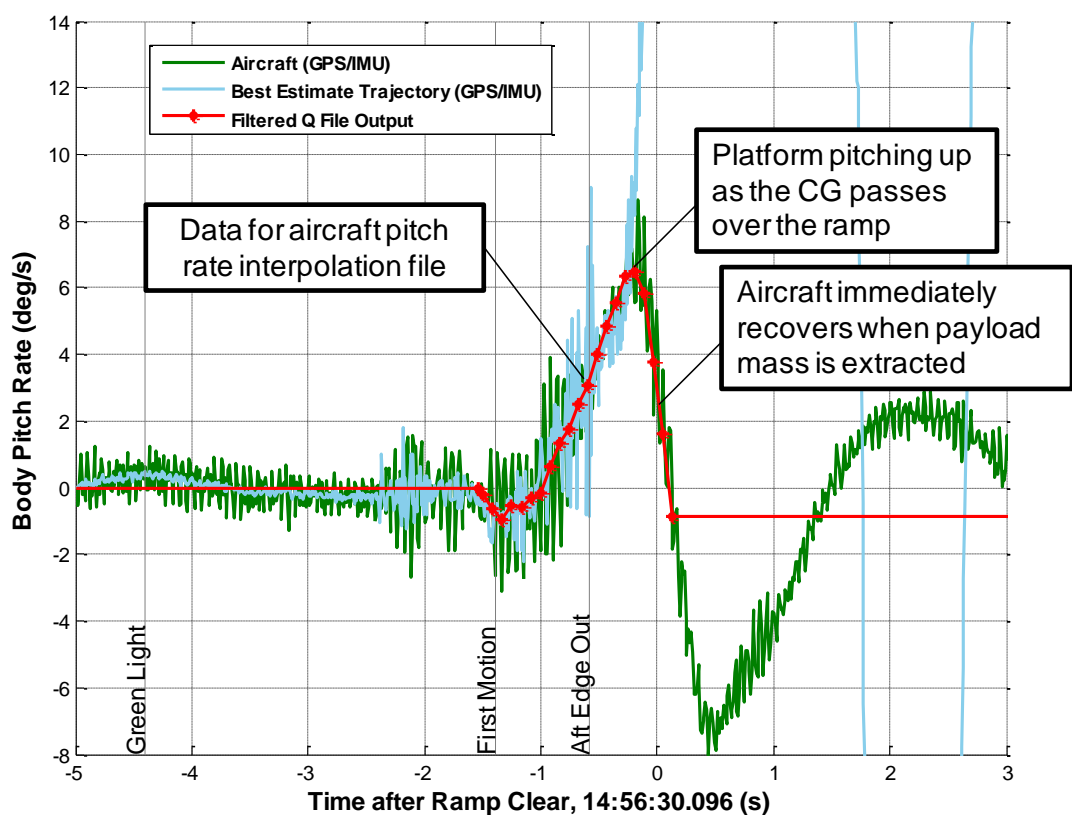

Figure 3. Measured pitch rate of C-130 and payload during CDT-2-3.

American Institute of Aeronautics and Astronautics 


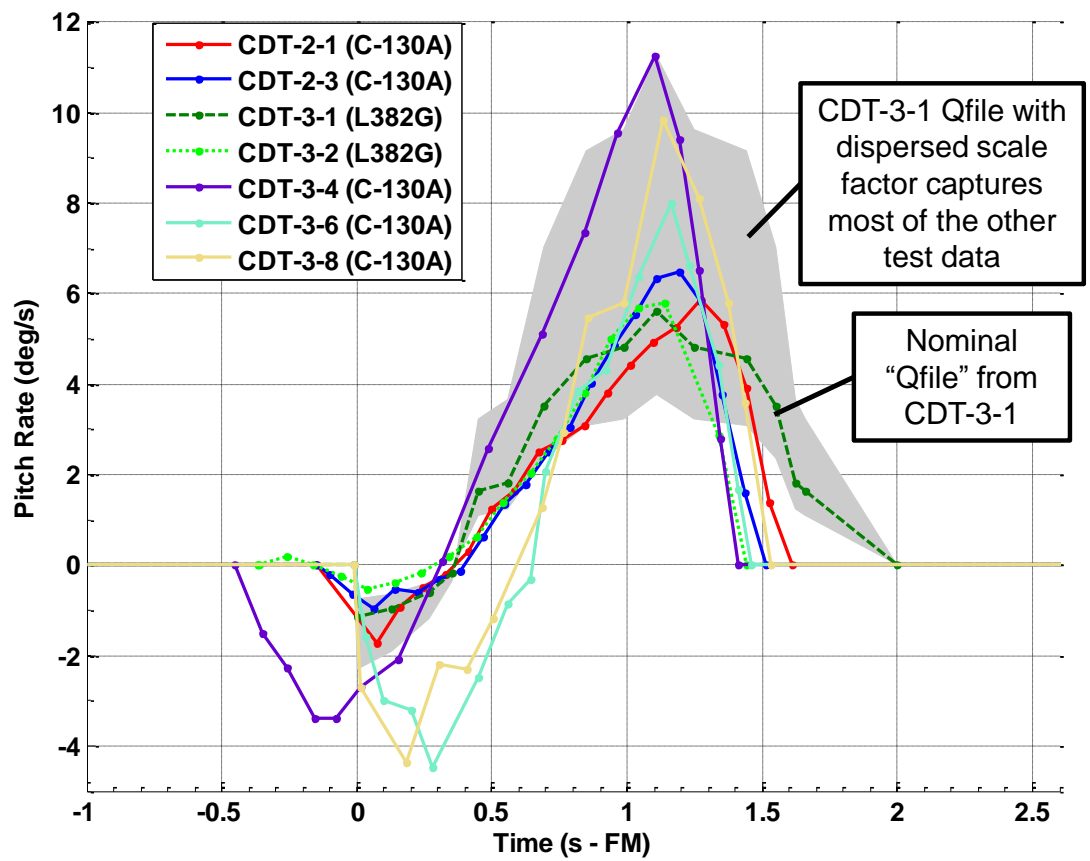

Figure 4. C-130 pitch rate comparison and Monte Carlo dispersion range.
A larger aircraft reacts less than a smaller one for a given extracted weight. The initial pitch attitude or "deck angle" during a C-17 extraction is "dialed in" to a particular value in order to maintain level flight. This value is a function of airspeed and total aircraft weight. Extraction airspeed is indirectly a function of altitude (extractions at $35,000 \mathrm{ft}$ require a higher airspeed because no flaps are used).

The C-17 has an onboard avionics system that records measurements of aircraft indicated airspeed, attitudes, and body rates. Rate data from this system is generally less noisy than any aircraft tray SPAN-SE, removing the need for smoothing. The pitch and pitch rate from several tests is shown

in Fig. 5. The tests at 25,000 ft have an initial deck angle between 3.5 and 5 degrees, with the lowest value due to a lower fuel state. Tests at 35,000 ft have an initial deck angle between 5 and 7 degrees (nominal $6 \mathrm{deg}$.). Note that the USAF test with a 60klb payload (cyan) was a special case where the locks were set to an extraction ratio of 0.5 (as opposed to 1.0) in order to simulate the loss of an extraction parachute. This extends the time for extraction and induces a larger reaction on the aircraft.
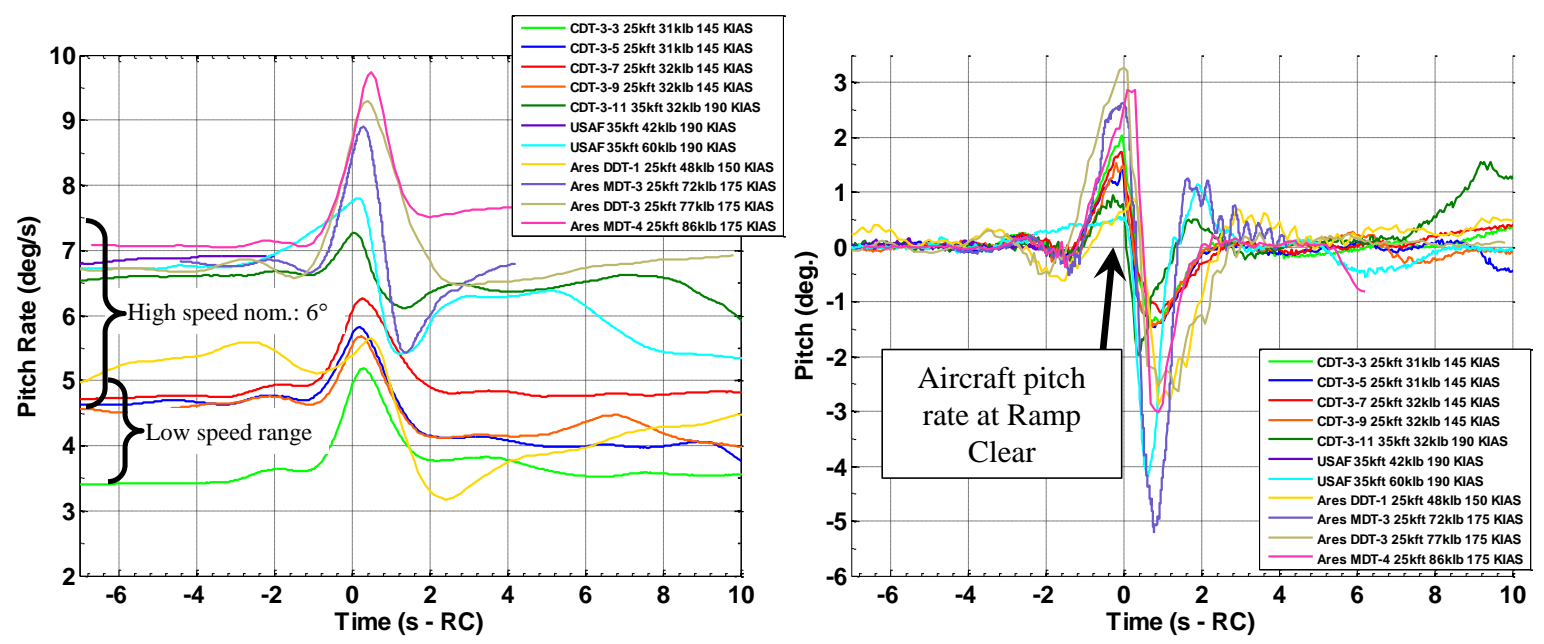

Figure 5. C-17 pitch attitude (left) and pitch rate comparison (right).

Because the CG shift during C-17 extraction is relatively small, the maximum pitch rate is only about $2 \mathrm{deg} / \mathrm{s}$; as opposed to approximately $10 \mathrm{deg} / \mathrm{s}$ for a C-130. The aircrew is generally instructed not to attempt to arrest the aircraft pitch rate during extraction. The comparison of measured C-17 pitch rate histories was used to determine Monte Carlo dispersions, as shown in Fig. 6. Sampled data from CDT-3-5 is used as a baseline and scaled with a dispersed factor in order to encompass expected performance. 


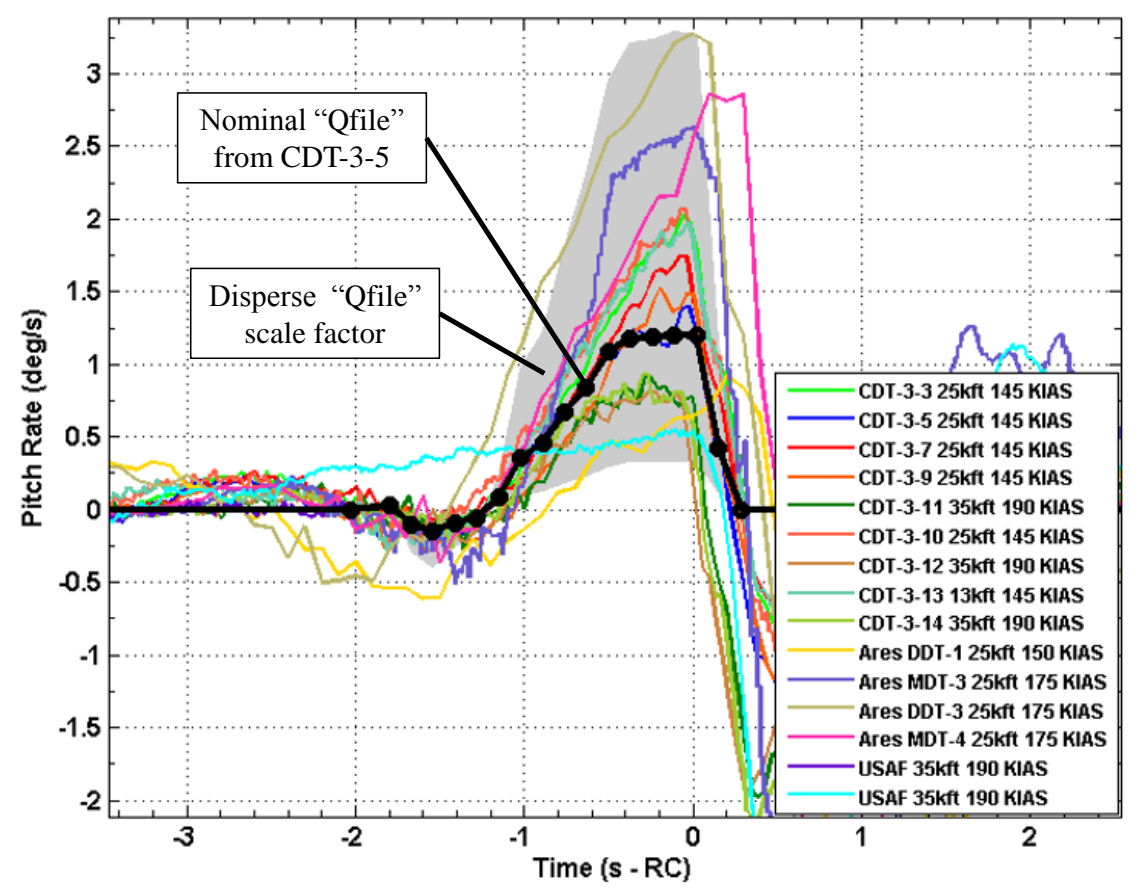

Figure 6. C-17 pitch rate comparison and Monte Carlo dispersion range.

Another consideration is the induced yaw rate on the test article. A correlation was observed between the amount of crosswind at altitude and the reaction experienced by the test vehicle after extraction. For example, TSE-1A had a large crosswind, yet the extraction parachute was initially aligned with the aircraft centerline, as shown in Fig. 7. The platform underwent a significant yaw during extraction, scraping the side rails during the exit and "fishtailing" after ramp clear. Although the test vehicle rolled completely over fairly quickly, this did not affect the success of the test.
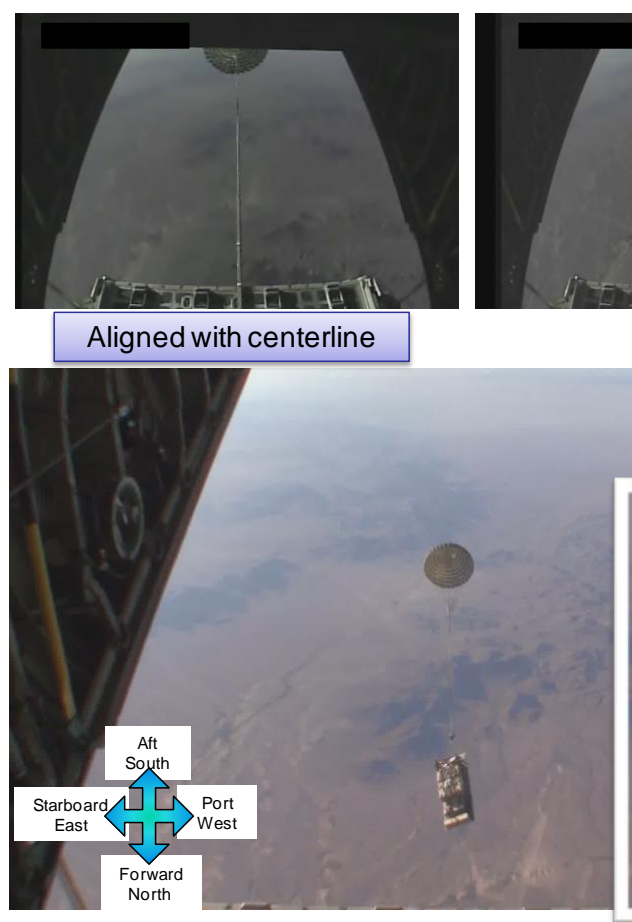

Figure 7. Example test article reaction to crosswind for TSE-1A.

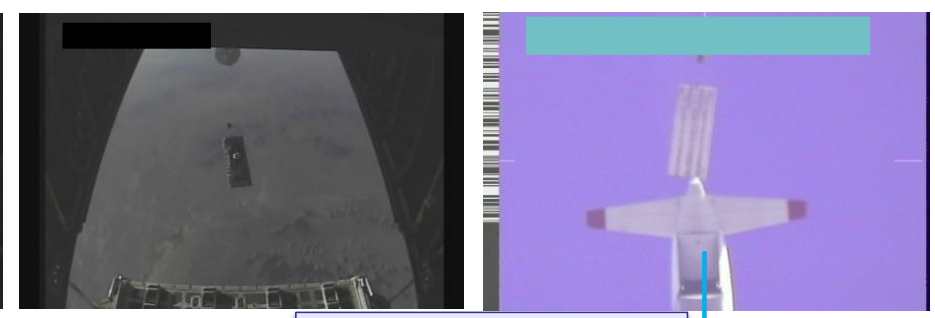

TSE-1A exhibited large negative yaw at extraction, then complete roll-over in positive direction.

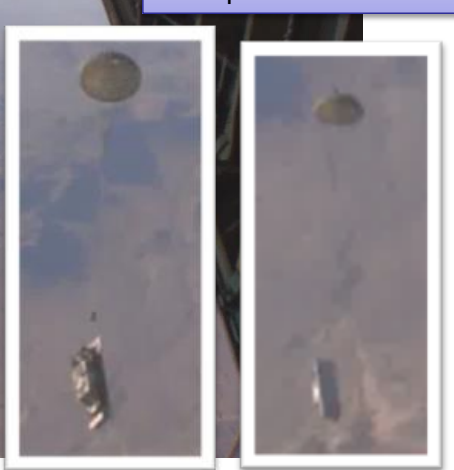

$\psi_{0}=-15.9^{\circ}$

Airspeed: $340 \mathrm{ft} / \mathrm{s}$

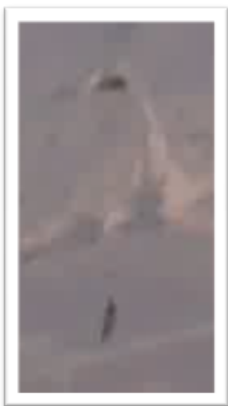

American Institute of Aeronautics and Astronautics 
This behavior can be explained by a vector examination of the total and relative velocities, as shown in Fig. 8. In order to maintain a northern ground track in the presence of a crosswind, the aircraft will induce a crab angle. The vehicle will be trimmed relative to the airflow, so the extraction parachute will naturally align with the vehicle centerline. However, as the test article is extracted, it will slow down relative to the parent aircraft and the extraction parachute will align with the new airspeed vector. After ramp clear, the extraction parachute will induce a moment on the platform, causing it to generate a sideslip angle.

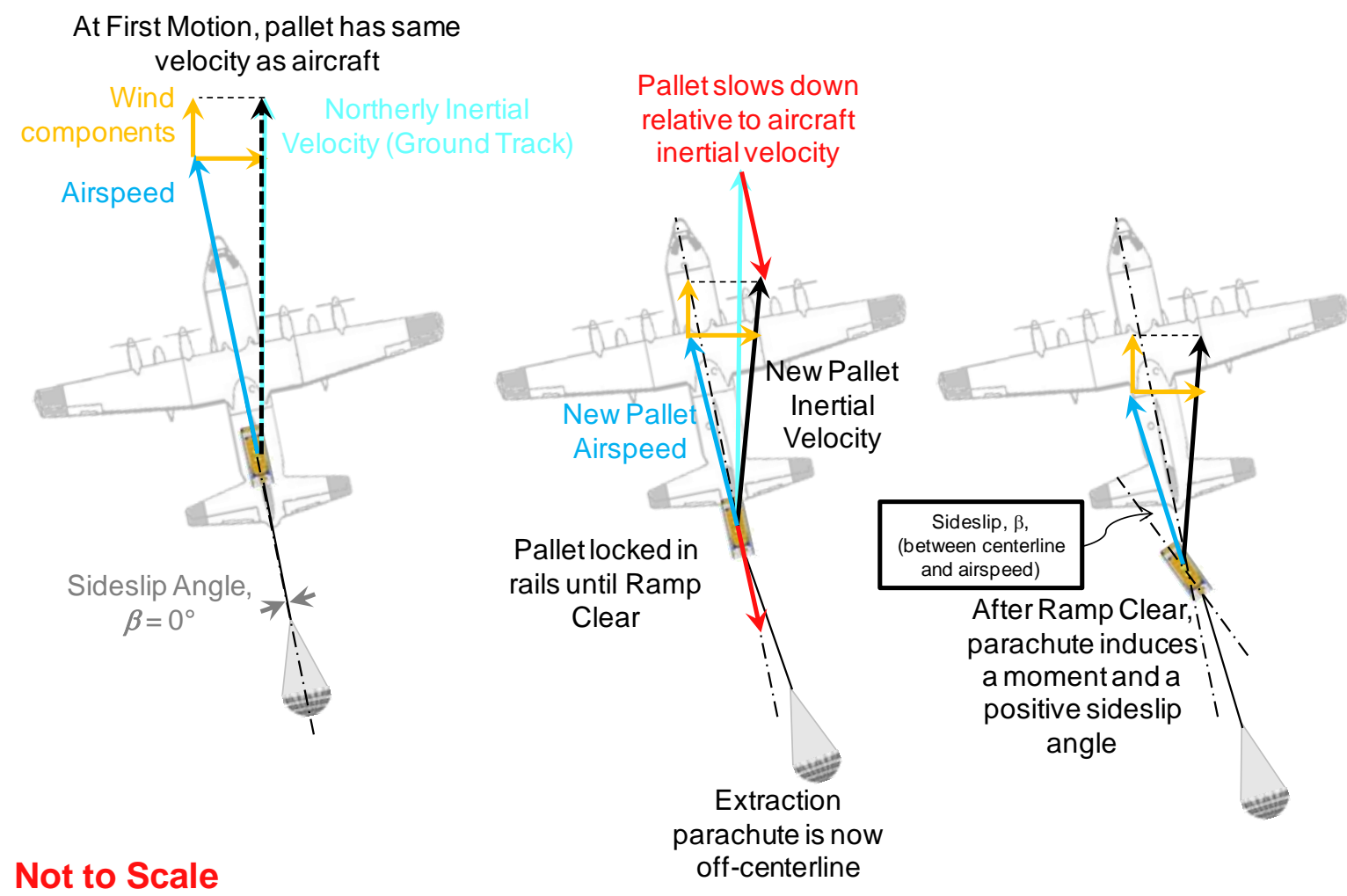

Figure 8. Horizontal motion induced by aircraft crab angle.

Payload attitude sensors used during Gen I were not able to accurately measure the yaw angle during extraction because they relied on magnetometers, with which the metal aircraft fuselage created interference. The initial heading for these tests were computed from the vector addition in Fig. 8. The initial yaw angle calculation was verified with direct data during Gen II. This was possible because the SPAN-SE which uses laser ring gyros which are not susceptible to magnetic interference.

There was some concern that a high crosswind might negatively affect the PCDTV/MDS repositioning; causing it to release and generate asymmetry between harnesses. The ADAMS simulation was modified by ATK to include crosswind effects (shown in Fig. 9) and an assessment was performed. The study showed that no significant risk was created. Although day-of-flight crosswind placards were considered, they were found to be difficult to implement due to wind shifts and ultimately were deemed unnecessary.

American Institute of Aeronautics and Astronautics 


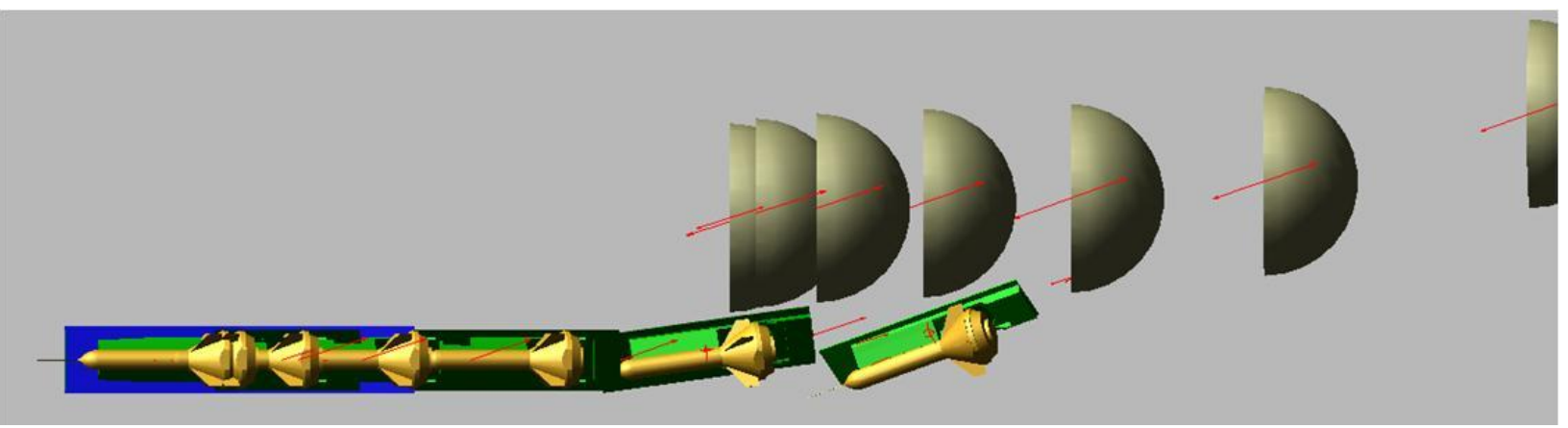

Figure 9. PCDTV/MDS ADAMS extraction simulation with extreme crosswind.

\section{Finite Mass and Infinite Mass Extraction Parachute Modelling}

One way of measuring extraction forces is with tow testing where no payload is extracted. Preflight simulation $C_{D}$ values were dispersed based on legacy US Air Force tow test data. ${ }^{12}$ Those limited tests measured the force generated by one or two extraction parachutes while being towed at a constant airspeed behind various aircraft. The sample load trace on the left of Fig. 10 seems to indicate an infinite mass over-inflation for a single parachute. However, the total load from a cluster of two parachutes (right) does not experience over-inflation and may better be modeled as a finite mass inflation. This may be due to interference between canopies or non-simultaneous inflation.

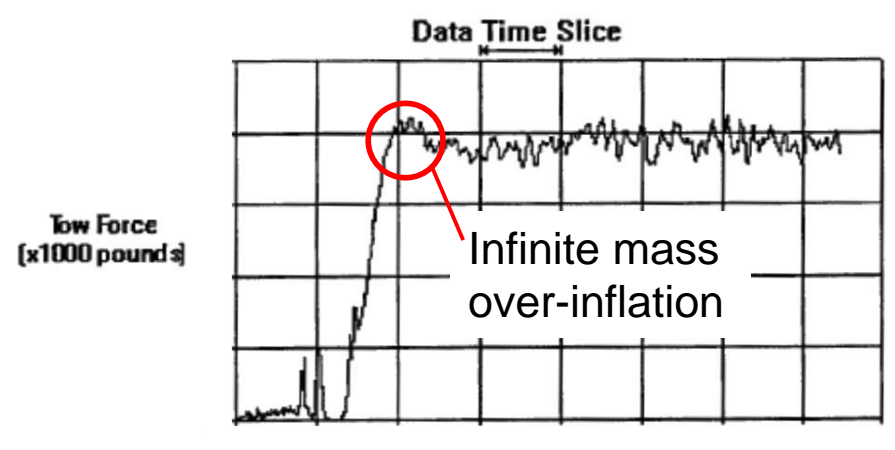

Ime from Tow Please [sec]

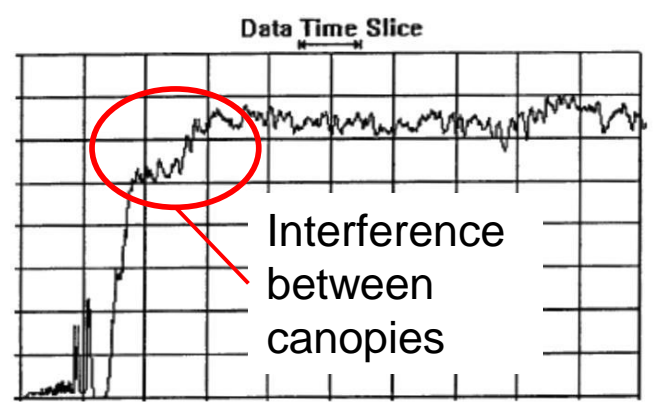

Ime from Tow Felease [sec]

Figure 10. Sample US Air Force tow test data for single parachute (left) and cluster (right).

A close examination of additional C-17 high-speed tow tests performed by Airborne Systems seems to confirm this observation. ${ }^{13}$ Onboard video from a single-parachute tow test shows a rapid over-inflation. The measured loads are divided by the instantaneous dynamic pressure (based on aircraft airspeed) to compute the drag area time history, $\left(\mathrm{C}_{\mathrm{D}} \mathrm{S}\right)(\mathrm{t})$, as shown in Fig. 11. The equation used to model drag area is described in detail in Ref. 14. An error function is used to determine inflation parameters that best match drag area growth model to the test data. ${ }^{15}$

American Institute of Aeronautics and Astronautics 

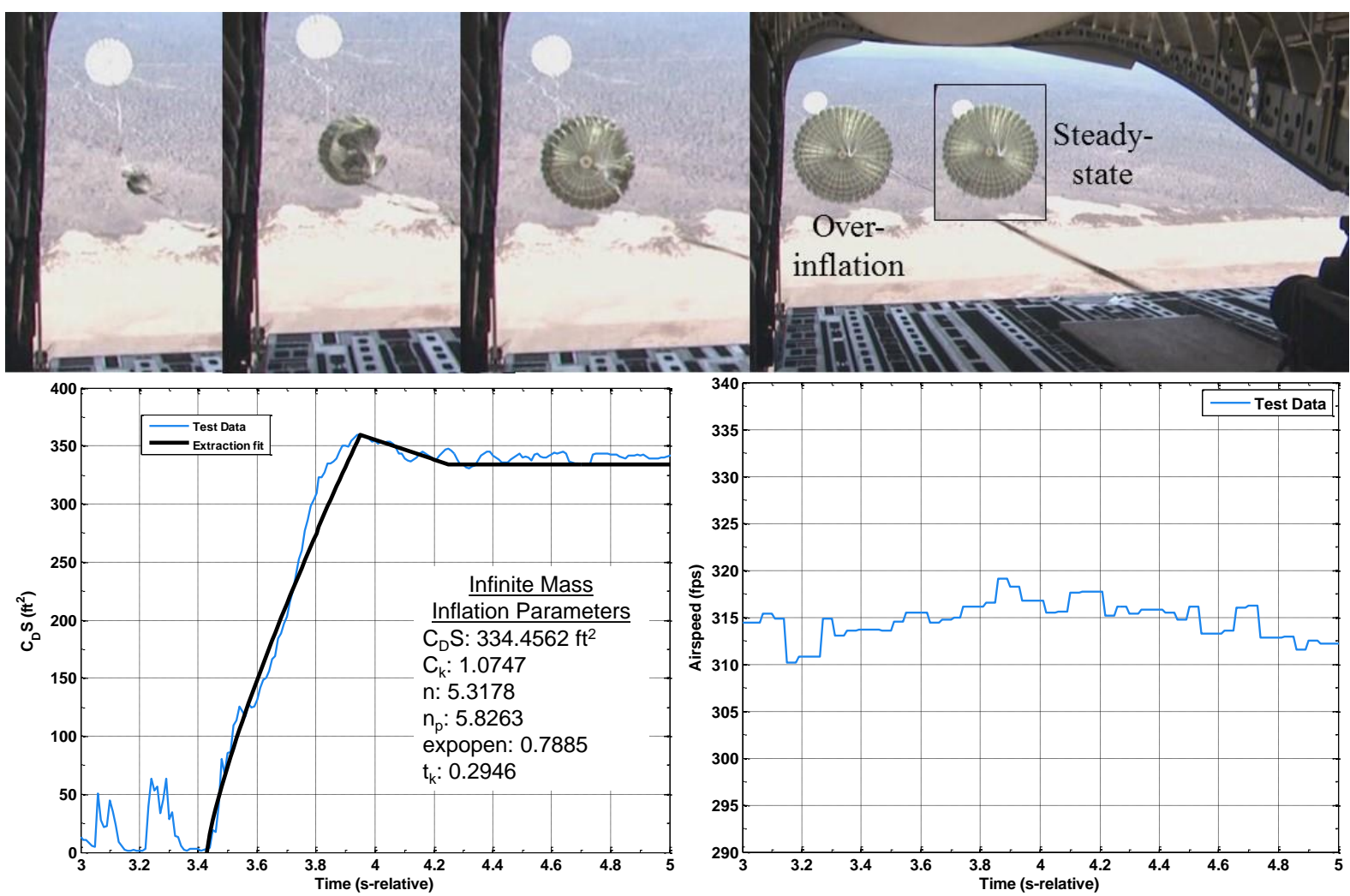

Figure 11. Single-parachute tow test inflation (top), best fit inflation (bottom left), and aircraft airspeed response (bottom right).

In contrast, the video from a two-parachute tow test does not indicate over-inflation, as shown in Fig. 12. The drag from two extraction parachutes was enough to reduce the aircraft airspeed, which may contribute to the finite mass inflation. In an actual extraction, the force of the extraction parachutes would only be transmitted to the aircraft briefly before overcoming the locks, allowing the payload to extract. Because the load cell only measures the total cluster load, the inflation parameters are for a composite inflation model (in contrast to the individual inflation method used in Ref. 15). 

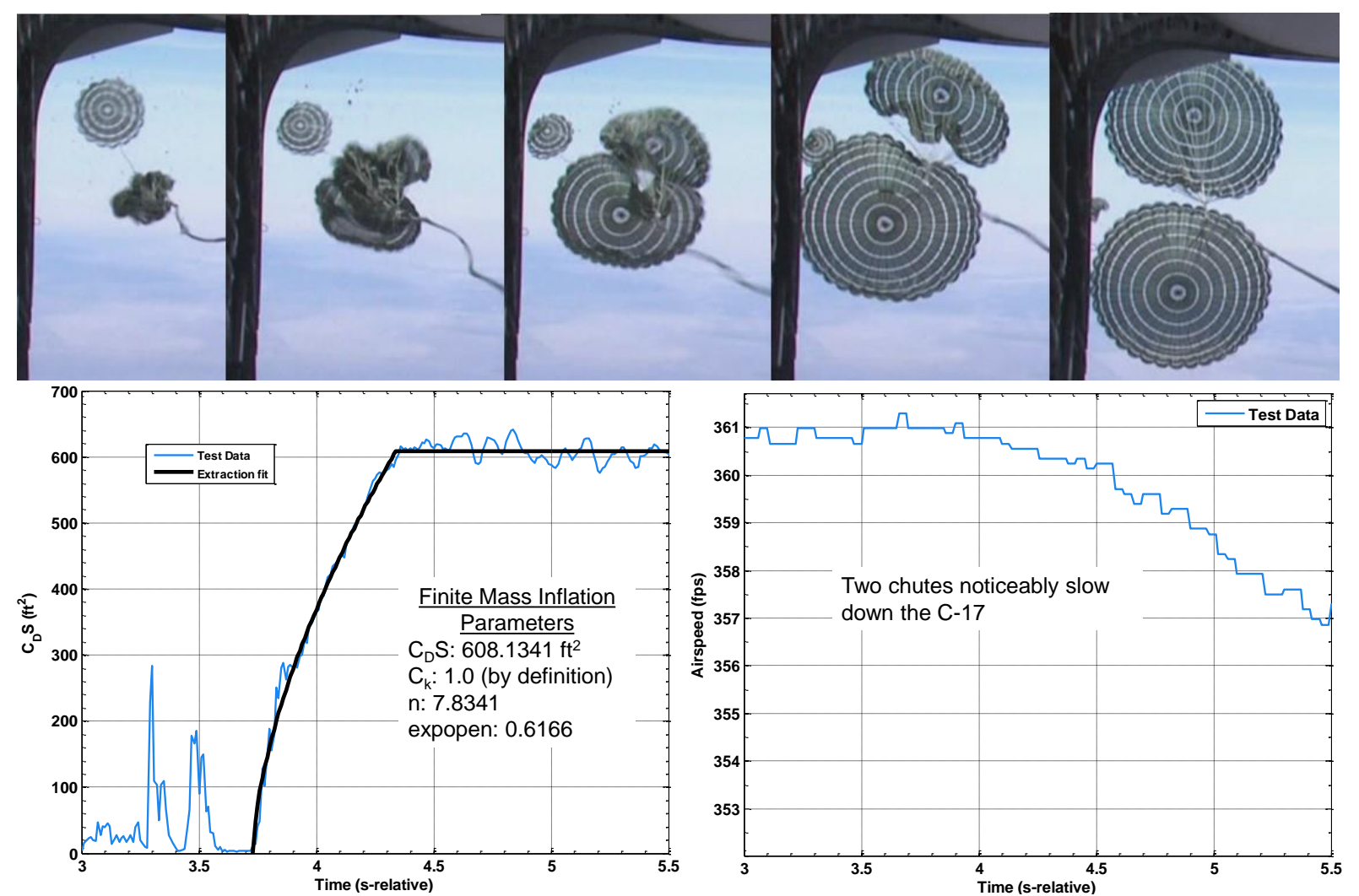

Figure 12. Dual-parachute tow test inflation (top), best fit inflation (bottom left), and aircraft airspeed response (bottom right).

One of the contributors to the effective finite mass composite inflation of a cluster is the non-simultaneous inflation of individual canopies. An extreme example of this is the partial collapse of one of the two extraction parachutes used during the Ares test designated Drogue Development Test (DDT)-2, shown in Fig. $13 .{ }^{16}$

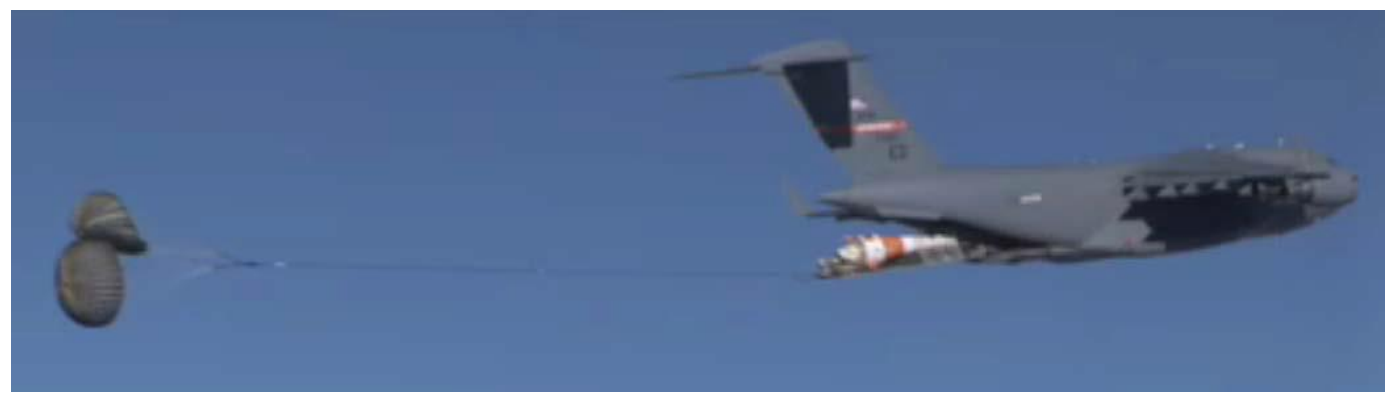

Figure 13. Partial collapse of one of two extraction parachute during Ares DDT-2.

\section{Indirect Extraction Load Measurement Methodology}

CPAS is not allowed to directly instrument the extraction parachute without significant certifications because it uses standard extraction hardware. The Ares program ${ }^{17}$ used the "item extraction" method and, therefore, installed a load pin for in-line force measurements. Example force data is shown in Fig. 14. The hesitation in initial inflation load during Main Development Test (MDT)-4 was due to the slow inflation of one of the three parachutes, as seen in Fig. 15. In fact, MDT-4 has two average values for extraction parachute drag area: one during the initial transient and another for full open.

American Institute of Aeronautics and Astronautics 


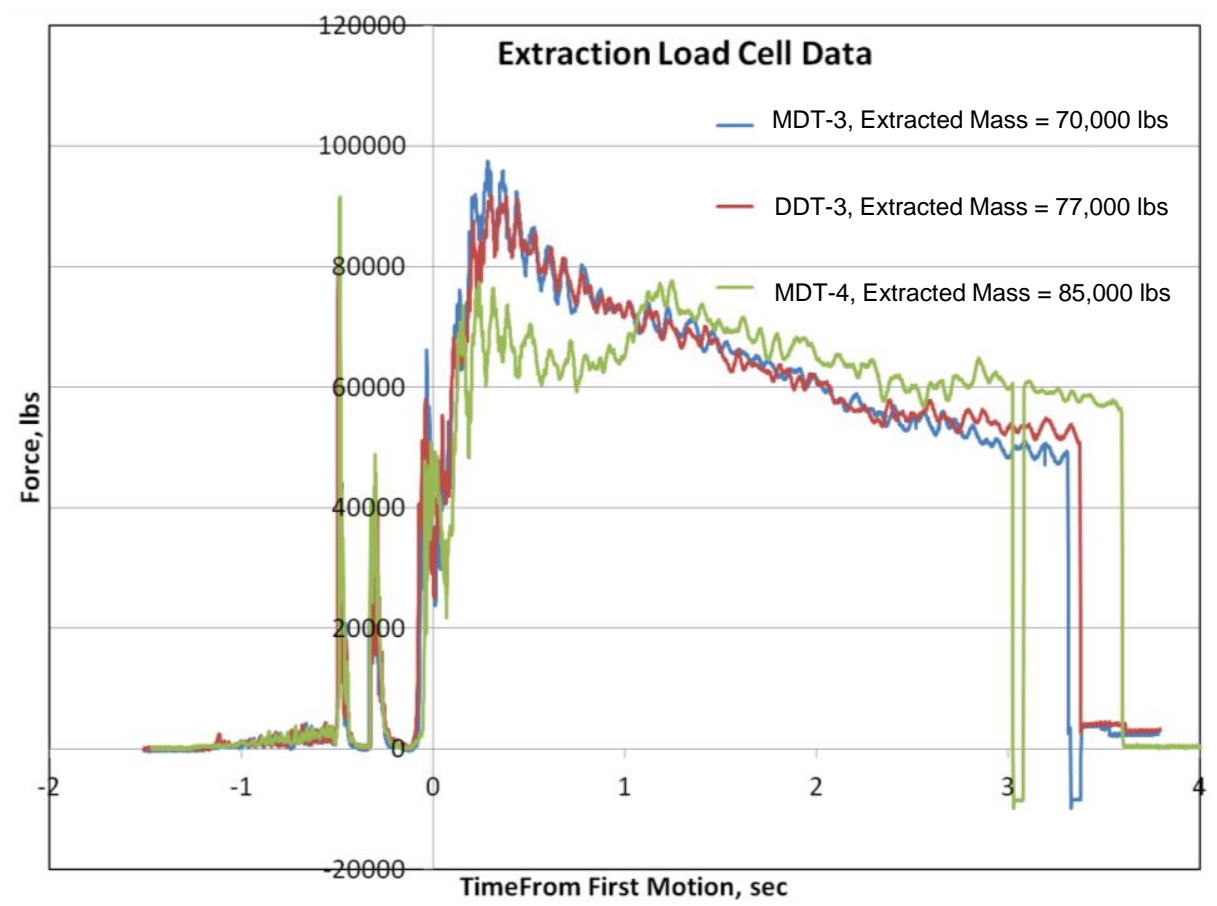

Figure 14. Direct measurements of extraction parachute force from the Ares program.

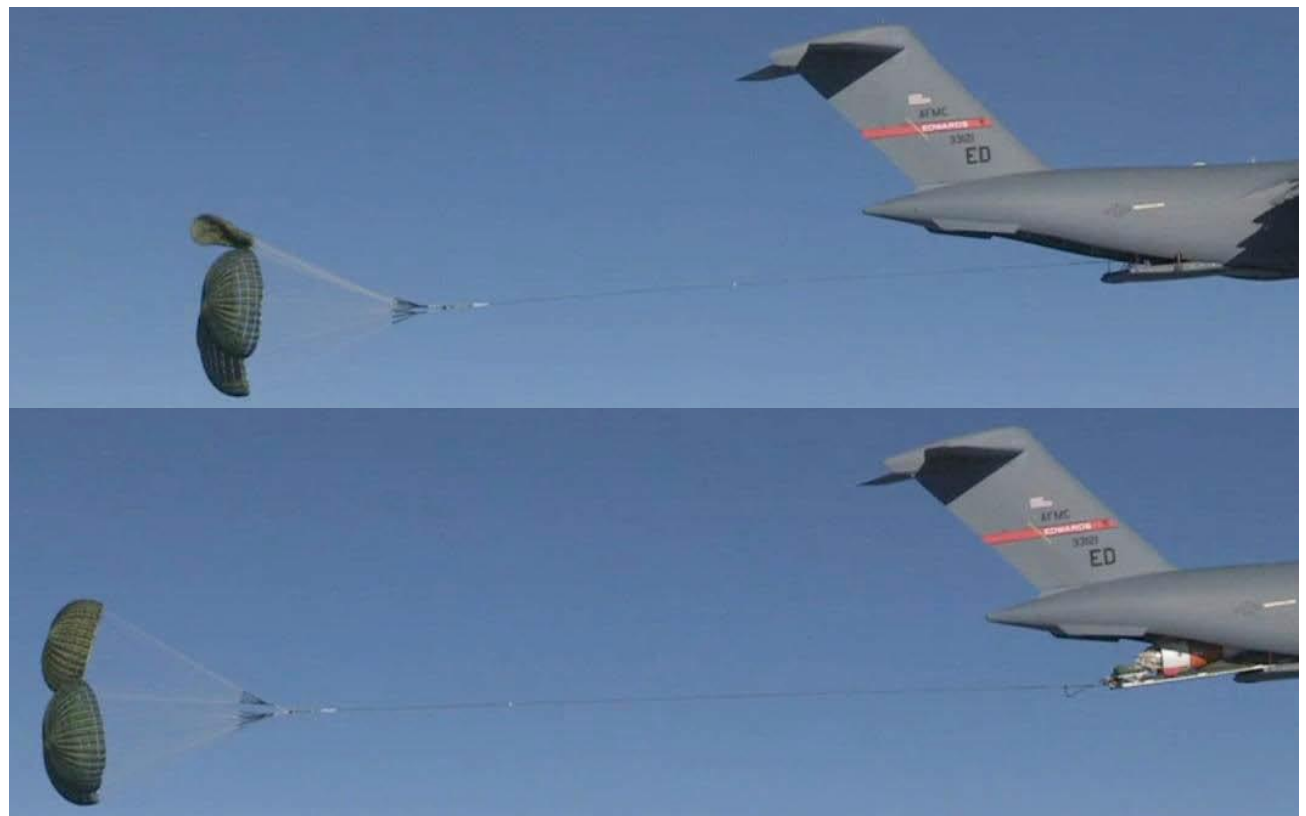

Figure 15. Lagging inflation of one of three extraction parachutes during Ares MDT-4.

The Ares program demonstrated the relationship between extraction force and measured acceleration for MDT4. ${ }^{18}$ The longitudinal acceleration of the payload can be estimated by dividing the extraction force by the extracted payload weight. The computed acceleration compares favorably to the acceleration reading in Fig. 16. The small differences shown prior to reaching the end of the ramp ( $2.13 \mathrm{~s}$ after first motion) can be attributed to the friction force that is not measured by the accelerometers. The load pin data are higher than the measured longitudinal acceleration after ramp clear because the additional lateral accelerations are experienced when the payload is free to rotate in the pitch plane.

This relationship permits estimation of extraction parachute performance when the necessary flight test data are available. First, the payload must have an appropriate accelerometer. Next, the dynamic pressure on the extracted 
payload needs to be accurately computed. High quality velocity measurements have only been possible on CPAS since the introduction of the SPAN-SE GPS/IMU. Previous GPS units always experienced a data dropout during extraction. The TSPI optical solution from ground cameras is not possible when the test vehicle is inside the aircraft.

An example of this calculation is presented for CDT-3-4, which used a single extraction parachute. The parachute extraction force can be approximated by multiplying the longitudinal vehicle acceleration, $\mathrm{a}_{\mathrm{x}}$, by the weight of the extracted vehicle, $\mathrm{W}_{\mathrm{v}}$, according to Eq. (1). The computed force (blue) is compared to the predicted force (grey) on the left of Fig. 17. The parachute force can then be divided

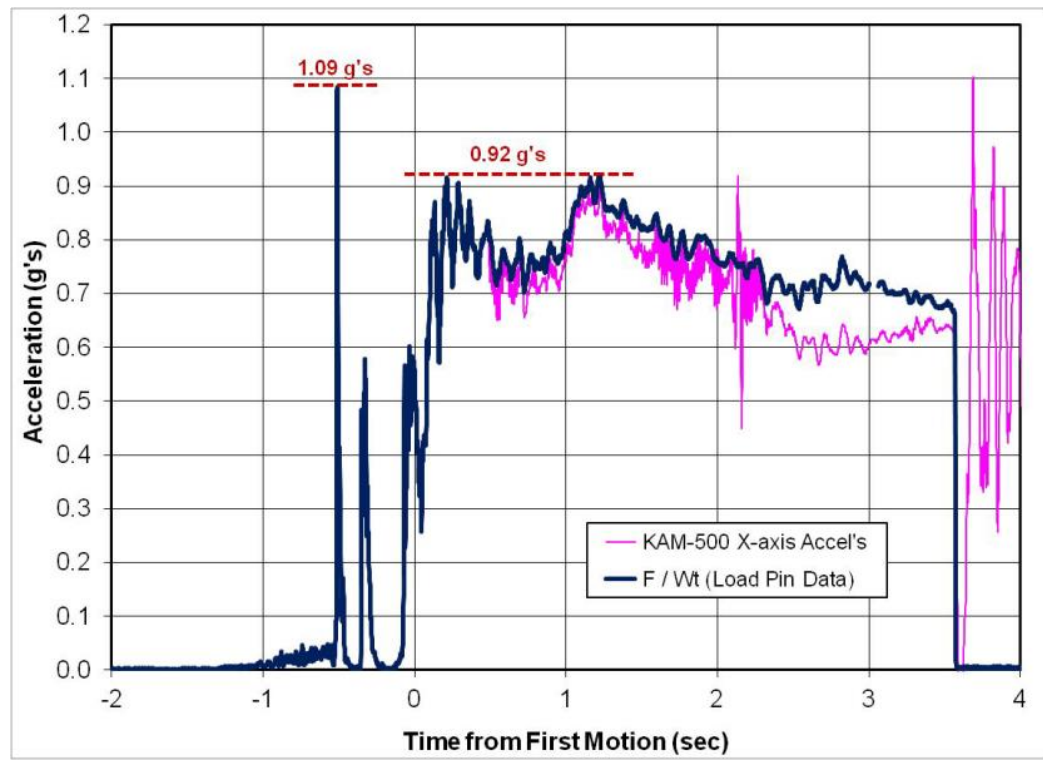

Figure 16. Comparison of longitudinal acceleration from accelerometer and from load pin (extraction force divided by payload weight) for Ares test MDT-4.

by the instantaneous dynamic pressure, $\overline{\mathrm{q}}$, (right) to compute the parachute drag area according to Eq. (2). This method of reducing flight data becomes less accurate as the vehicle performs a "gravity turn" after extraction.

$$
\mathrm{F} \approx \mathrm{a}_{\mathrm{V}} \cdot \mathrm{W}_{\mathrm{V}}
$$
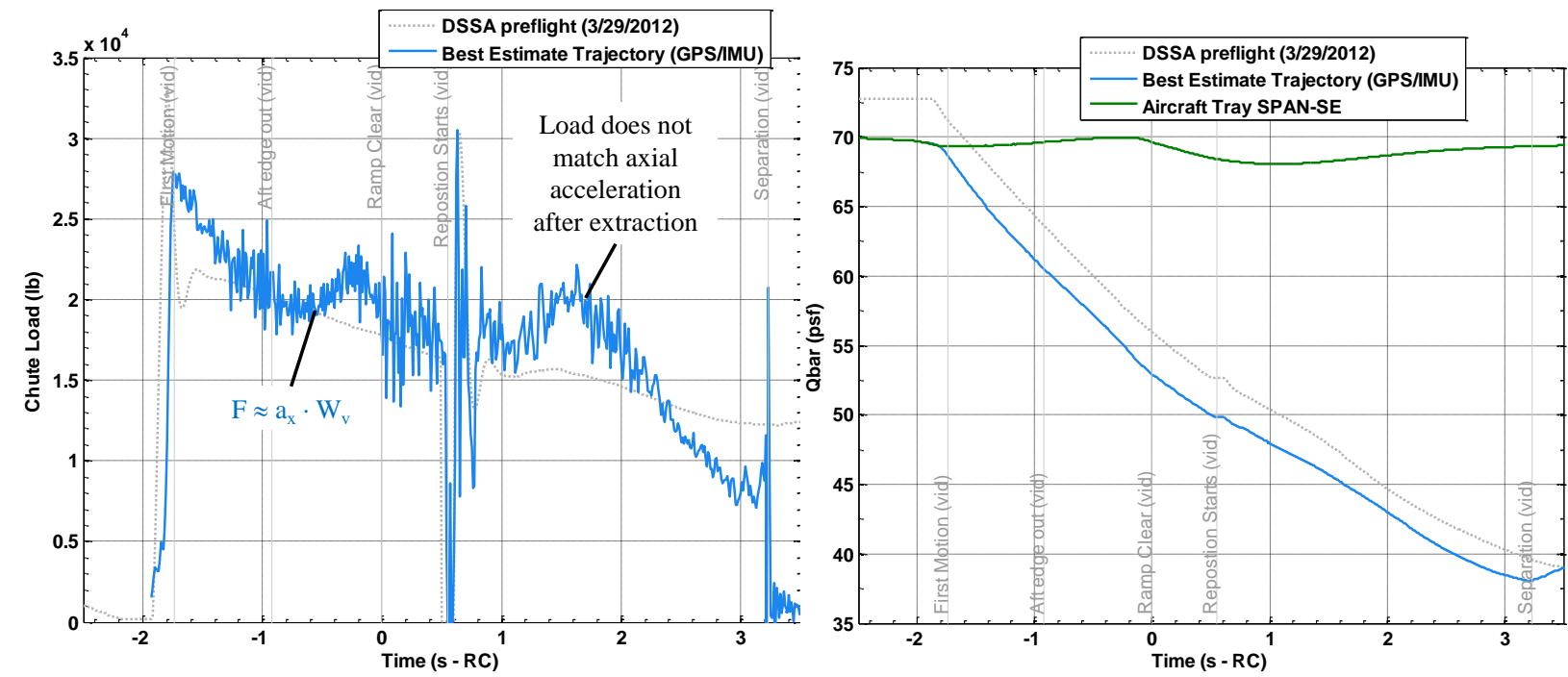

Figure 17. CDT-3-4 extraction parachute force computed from acceleration (left) and test vehicle dynamic pressure (right).

$$
\mathrm{C}_{\mathrm{D}} \mathrm{S} \approx \frac{\mathrm{F}}{\overline{\mathrm{q}}}
$$

The instantaneous drag area $\left(\mathrm{C}_{\mathrm{D}} \mathrm{S}\right)$ is plotted on the left of Fig. 18. An over-inflation is visible, which is consistent for a single-parachute extraction. The steady-state drag area of the fully-inflated extraction parachutes should generally be constant, except for buffeting due to the aircraft wake, a sideslip effect, and any non-standard deployment issues.

American Institute of Aeronautics and Astronautics 
The mean cluster $\mathrm{C}_{\mathrm{D}} \mathrm{S}$ for this test was computed as $354.0 \mathrm{ft}^{2}$. The corresponding mean drag coefficient (right) is therefore 0.575 , based on the reference area of the $28 \mathrm{ft} \mathrm{D}_{\mathrm{o}}$ extraction parachute.
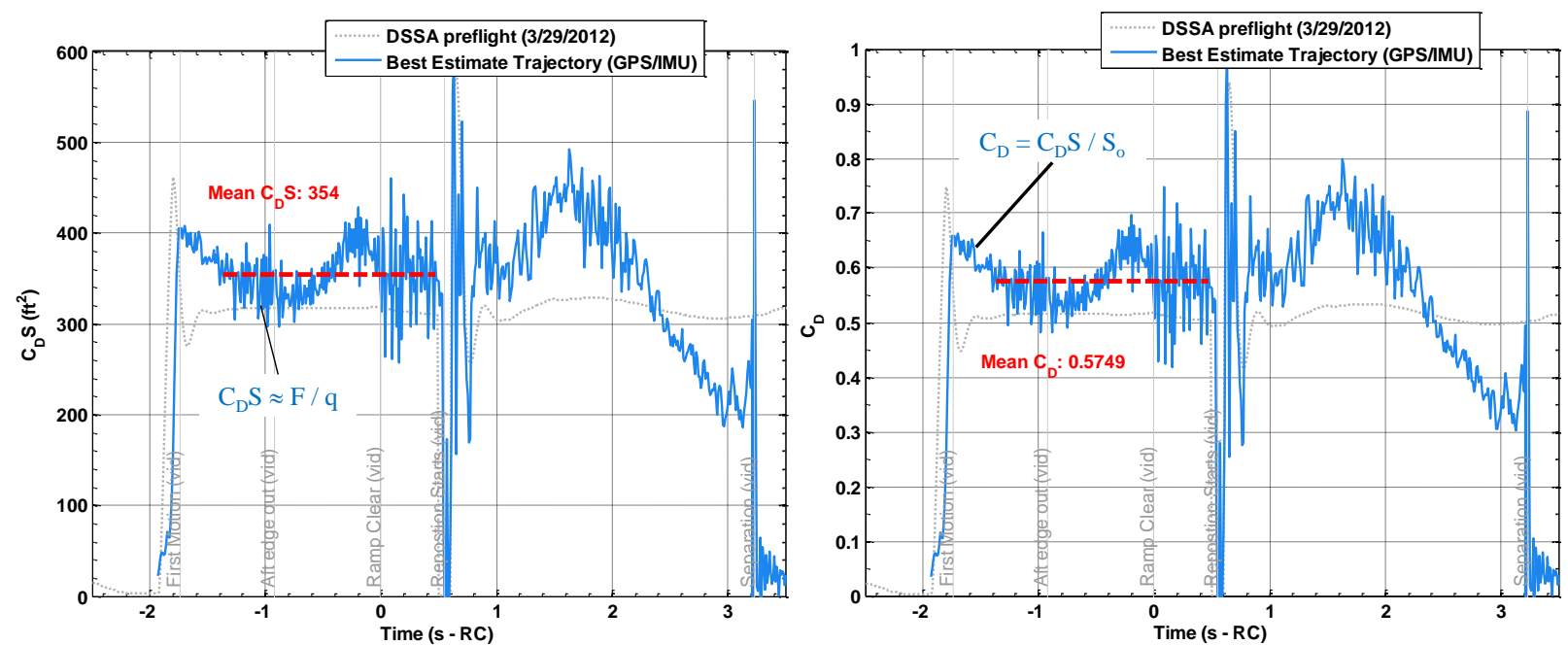

Figure 18. CDT-3-4 extraction parachute drag area (left) and drag coefficient (right).

\section{Standard Altitude Extraction Parachute Results}

Extractions from a C-130 or C-17 at 25,000 ft or below use standard Low Velocity Aerial Delivery (LVAD) procedures. The number of required (unreefed) $28 \mathrm{ft} \mathrm{D}_{\mathrm{o}}$ extraction parachutes is based on the total payload weight and aircraft type. Extractions above 25,000 ft (only possible on a C-17) required additional certification (next section).

A statistical assessment of the one- and two-parachute drag data was performed, similar to the procedure used in the CPAS Model Memo and described in Ref. 19. The results, plotted in Fig. 19, show the trends. For a given type of aircraft, clusters of two extraction parachutes are less efficient than a single extraction parachute, as expected from experience with the CPAS parachute clusters. For a single extraction parachute there is little difference between the canopy drag area behind a C-130 or C-17 due to the strong influence by the wake from either aircraft. However, when two extraction parachutes are used on a C-130, the overall drag is higher than for a C-17. This is most likely because the C-130 fuselage is narrower, allowing for part of the cluster to lie outside the aircraft wake, as shown in Fig. 20. Likewise, a cluster of three extraction parachutes are large enough to extend outside the $\mathrm{C}-17$ wake, and become more efficient, as shown in the Ares test designated MDT-3 in Fig. $21 .^{20}$

American Institute of Aeronautics and Astronautics 

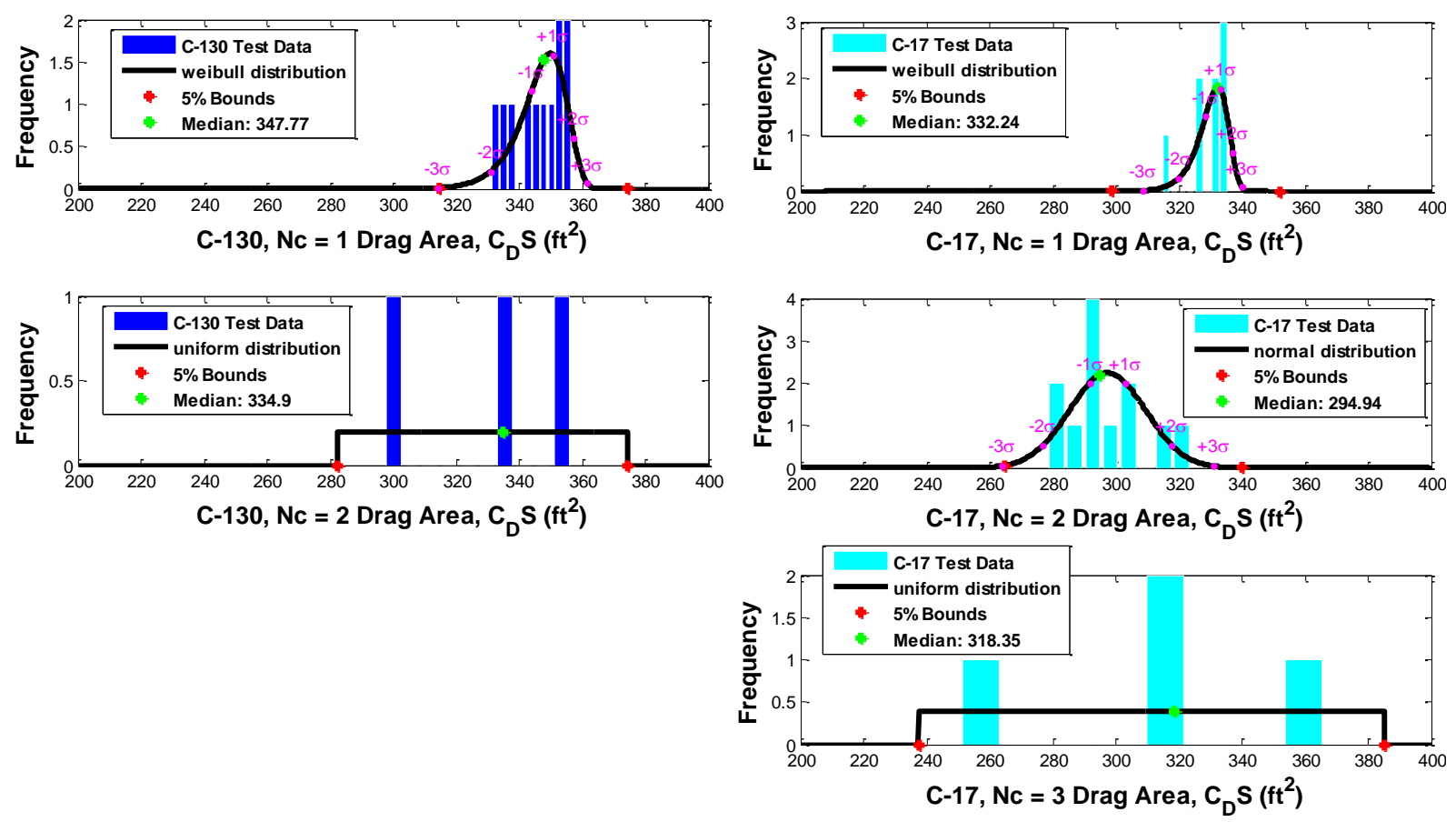

Figure 19. Drag area modeling parameters of $28 \mathrm{ft} D_{0}$ extraction parachute (unreefed) based on type of aircraft and number of canopies.

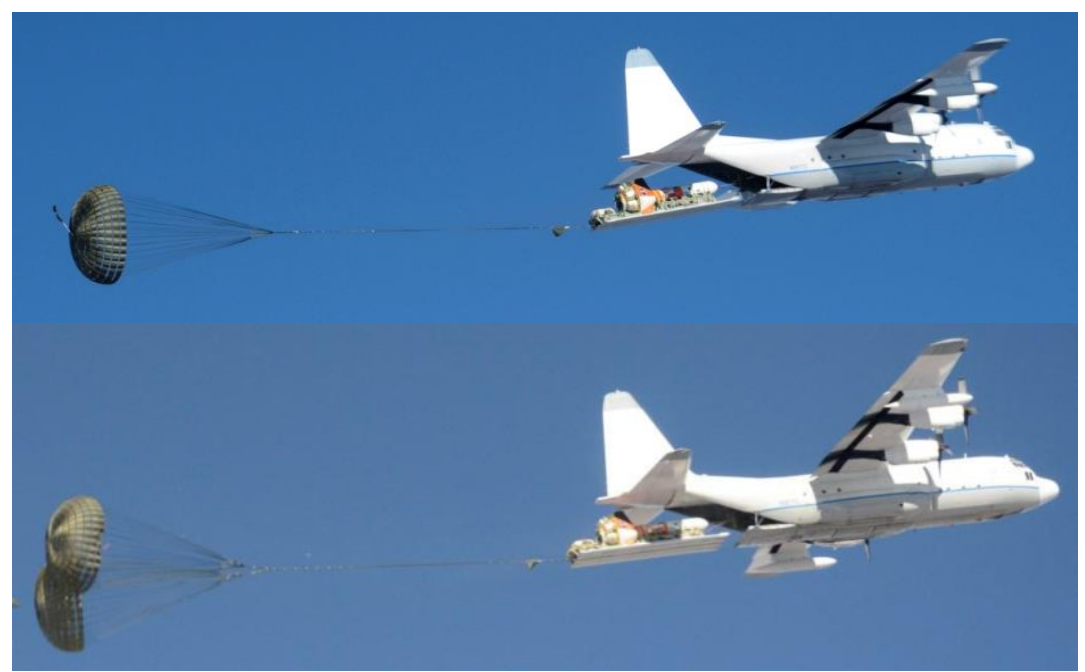

Figure 20. C-130 extraction with one and two $28 \mathrm{ft}$ Do canopies on CPAS CDT-3-4 and CDT-3-6.

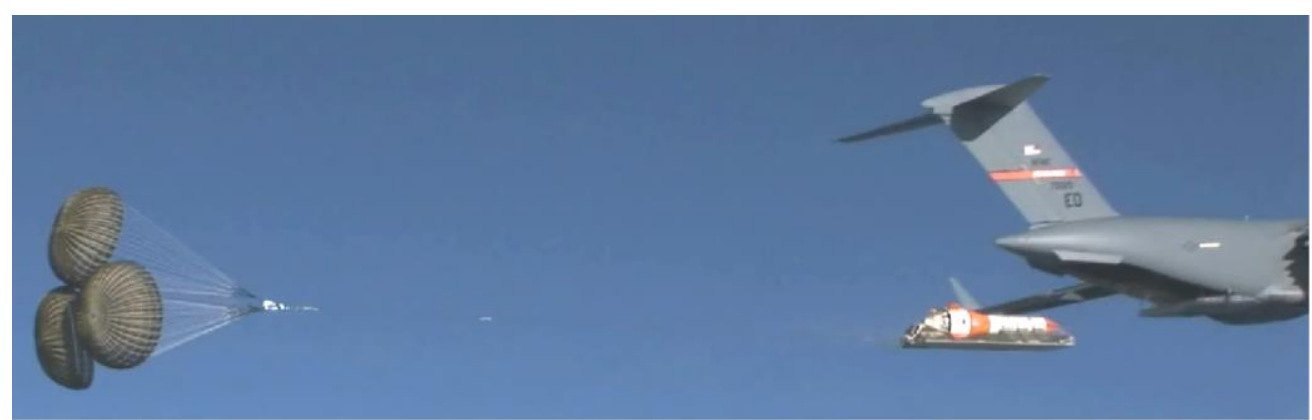

Figure 21. C-17 extraction with three $28 \mathrm{ft} \mathrm{D}_{0}$ canopies on Ares MDT-3. 
When enough single-canopy drag data became available to produce a non-uniform distribution, the Weibull distribution was chosen to model the longer tail to the left. This may indicate the relatively less likely occurrence of a low-performing extraction parachute due to a non-orderly deployment. The normal distribution was used for the C-17 twocanopy dispersion. Each distribution is bounded using an Engineering Factor of $5 \%$ beyond its extreme points.

Only a limited number of C-130 extractions had adequate payload instrumentation to determine parachute inflation parameters. Therefore, inflation parameter distributions are not available for the C-130. The only unreefed configuration which currently has a statistically relevant number of inflation reconstructions is a cluster of two extraction parachutes from a $\mathrm{C}-17$. As in the CPAS Model Memo, distributions were established to best fit the data. A twodimensional convex hull algorithm was applied to only utilize dispersed points within a region near flight test experience, as shown in Fig. 22. During Monte Carlo dispersions, the pair of parameters for each cycle are tested against the convex hull shape. ${ }^{19}$ Pairs which lie outside the boundary are re-drawn as necessary until all points lie within the boundaries.

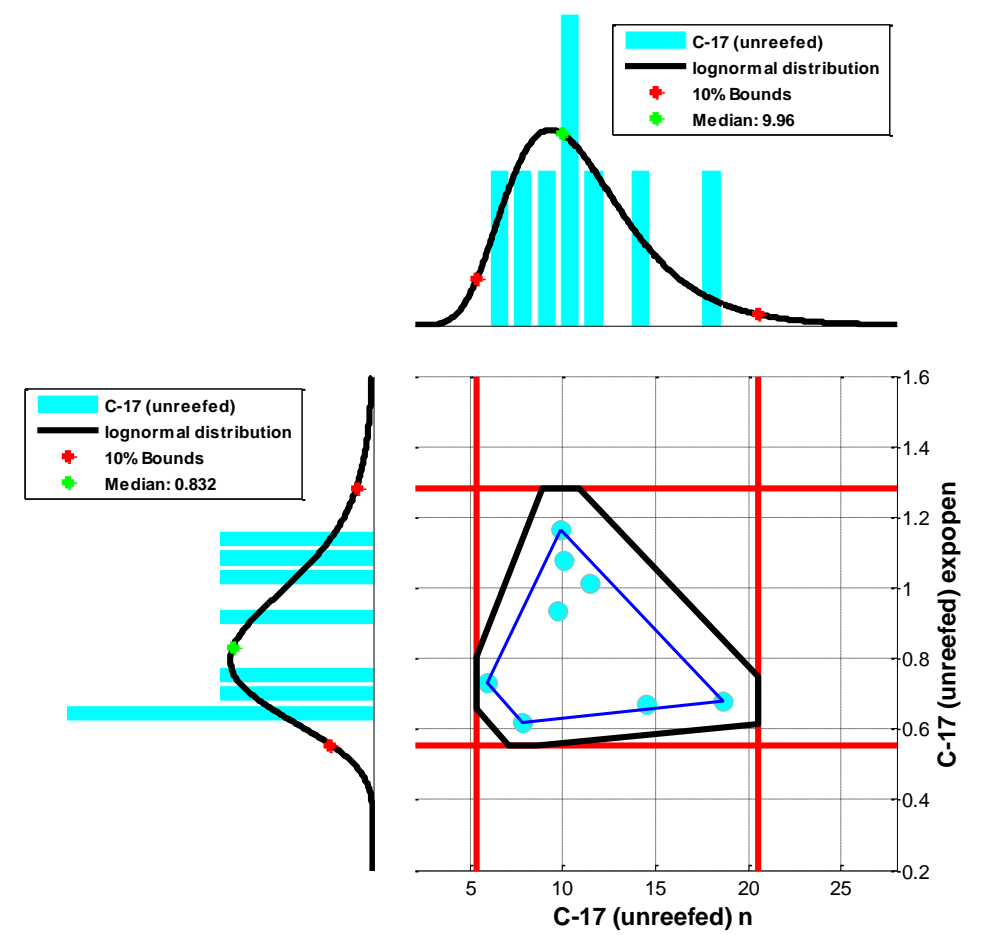

Figure 22. Distribution of C-17 extraction with $2 \times$ Unreefed 28 ft Do canopies.

\section{High Altitude Extraction Parachute Results}

In order to reduce inflation loads during high speed extractions (necessary for altitudes up to $35,000 \mathrm{ft}$ ), the $28 \mathrm{ft}$ $\mathrm{D}_{\mathrm{o}}$ extraction parachute has been reefed to a theoretical $70 \%$ reefing ratio (actual performance was estimated at $54 \%$ ). Individual reefed extraction parachutes were tow tested twice, but extraction of CPAS payloads require two extraction parachutes.

CDT-3-11 was the first CPAS test conducted at 35,000 and $190 \mathrm{KCAS}$, using a cluster of two reefed extraction parachutes as shown in Fig. 23.

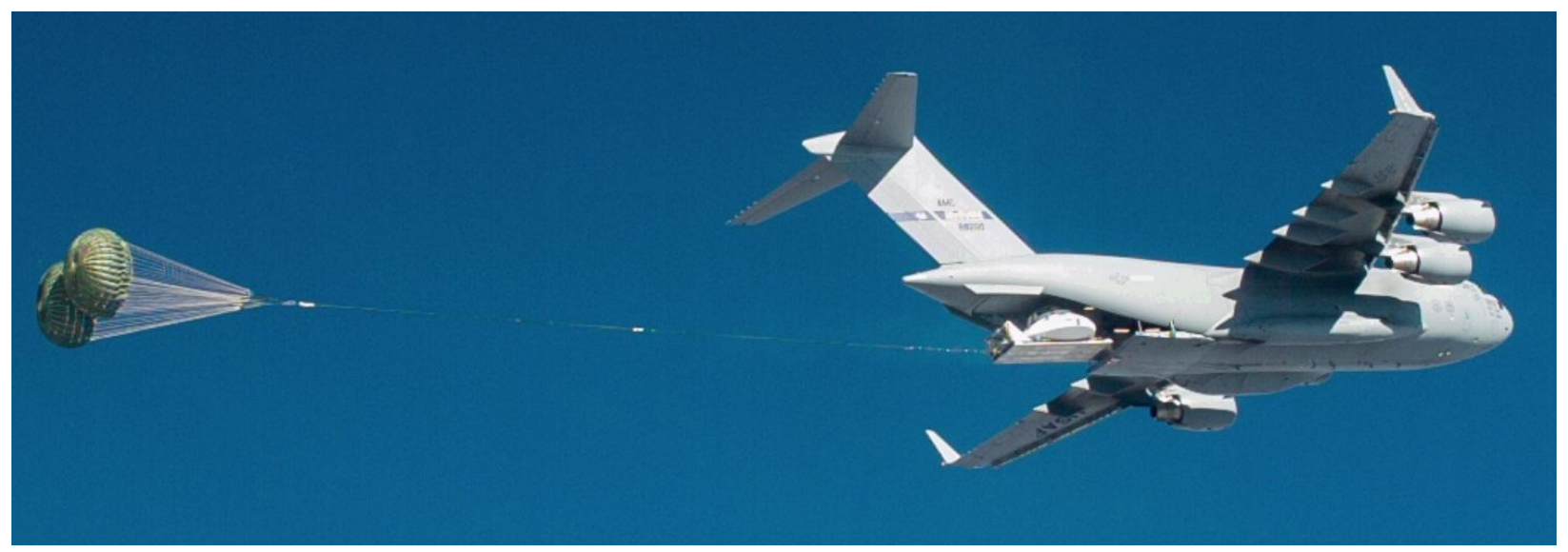

Figure 23. Cluster of two reefed extraction parachutes during CPAS test CDT-3-11. 
Video onboard the C-17 captured an extraction line "whip" event which occurred as the extraction parachutes were deployed. This lifted the extraction attach mechanism about twenty degrees and slammed it back down, causing some damage to the C-17 deck. This effect has been seen on previous tests, ${ }^{21}$ but not of this severity, possibly because the higher altitude and airspeed generated more energy. The traveling wave in the extraction line is highlighted in Fig. 24. This whipping effect was mitigated by modifying the extraction parachute bags and lashing the extraction line to the deck with breakaway ties. Additional modifications were made to the PTV/CPSS extraction technique, as discussed in Ref. 9.

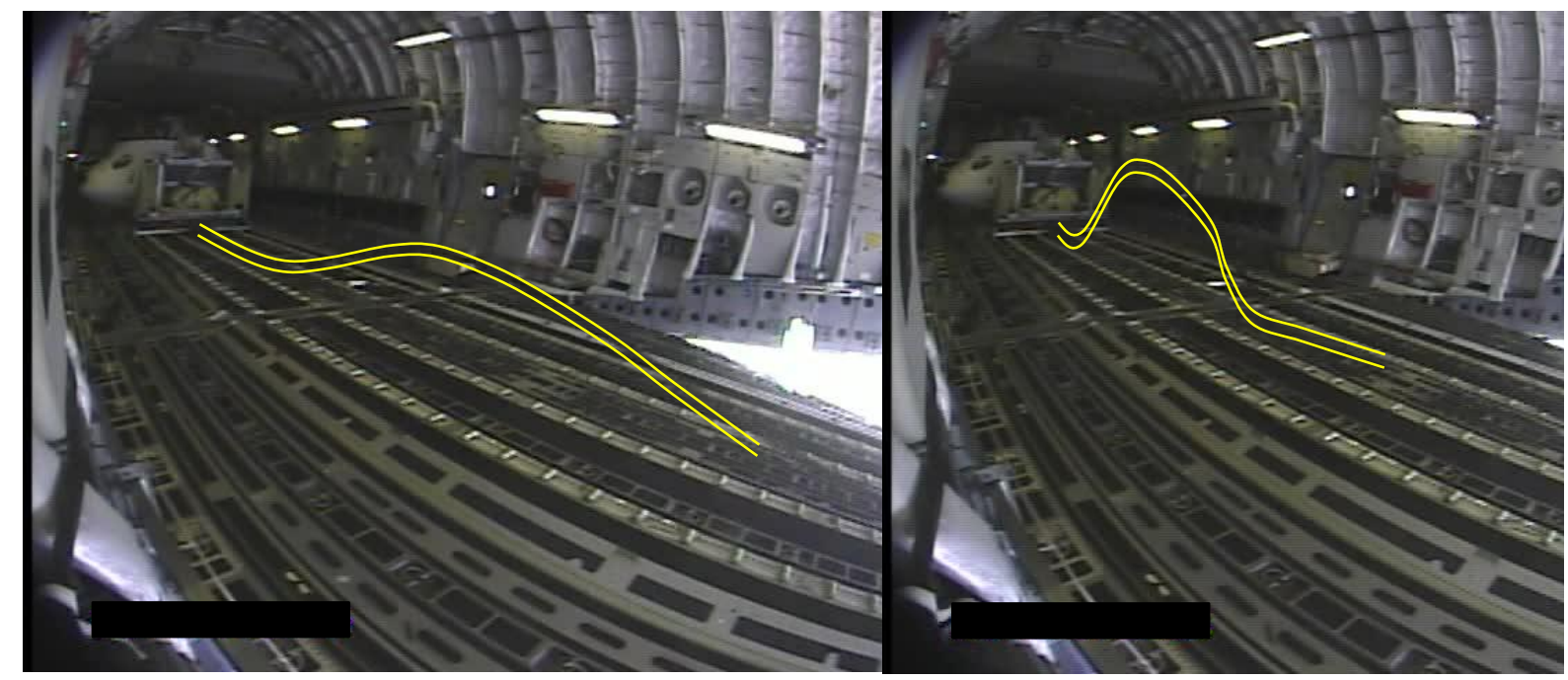

Figure 24. Extraction line "whip" effect on CDT-3-11.

The concern regarding the higher energy involved in high-altitude extractions prompted Airborne Systems to simulate snatch forces using LS-DYNA before the next planned test, CDT-3-12. This analysis seemed to indicate the possibility of exceeding hardware limits due to inertial loads, and a test stand-down was subsequently ordered. In order to test this assumption directly, two high-altitude tow tests were conducted. These tests provided valuable inflation data and refinement of the lashing procedure and bag modifications. Directly measured peak loads during both tests were within acceptable bounds, so high-altitude extractions were approved with the corrective measures in place. CDT-3-12 was eventually conducted without issue.

Due to the low sample size, all reefed data points are grouped together for the performance statistics, plotted in Fig. 25. Because the reefed configuration has a higher uncertainty, the Engineering Factor used to bound the drag area distribution was increased to $10 \%$.

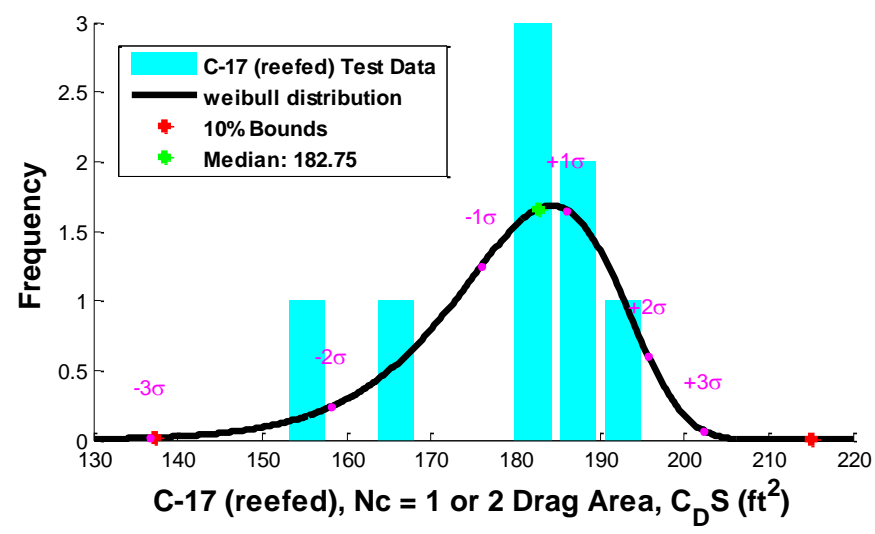

Figure 25. Drag area modeling parameters of reefed 28 ft $D_{0}$ extraction parachute.

American Institute of Aeronautics and Astronautics 
The three-dimensional view of other inflation parameters is shown in Fig. 26. Because this is an infinite mass inflation, the fill time is parameterized by the peak fill constant $\left(n_{p}\right)$, which can be converted to the actual fill constant (n). A convex hull is generated around the test points specifying a volume. Any randomly drawn parameters outside of this volume are redrawn in Monte Carlo trials. ${ }^{19}$

\section{Conclusion}

The aircraft response during test article extraction is modeled by dispersing a baseline pitch rate curve such that the result is within flight test experience. The $\mathrm{C}-130$ pitch response has a higher amplitude than that of the larger $\mathrm{C}$ 17. Crosswind effects were evaluated, but test article yaw was determined to be of lower significance than pitch plane dynamics.

A method of reducing extraction parachute loads from indirect data is presented. The extraction parachute inflation parameters were computed using either finite or infinite mass techniques developed for CPAS test parachutes.

Extractions at low altitude indicate finite mass inflation, possibly due to non-simultaneous inflations. High altitude inflations are modeled as infinite mass.

\section{Acknowledgments}

The author wishes to acknowledge Ron King and the Ares parachute project for providing test reports. Keith Anderson of ATK was instrumental in providing the ADAMS capability to CPAS. Franz Ravello of Edwards AFB provided crucial C-17 data. David Peterson, Scott Roland, Rob Sinclair, Ben Tutt, and Vladimir Drozd at Airborne Systems provided flight test data, video footage, and helpful insight. 


\section{References}

${ }^{1}$ More, J. W. and Romero, L. M., “An Airborne Parachute Compartment Test Bed for the Orion Parachute Test Program,” $22^{\text {nd }}$ AIAA Aerodynamics Decelerator Systems Technology Conference, Daytona Beach, Florida, March 2013, AIAA paper 2013-1289.

${ }^{2}$ More, J. W. and Fraire, U. J., "A Boilerplate Capsule Test Technique for the Orion Parachute Test Program," $22^{\text {nd }}$ AIAA Aerodynamics Decelerator Systems Technology Conference, Daytona Beach, Florida, March 2013, AIAA paper 2013-1290.

${ }^{3}$ Machín, R.A. and Evans, C.T., "Cluster Development Test 2 an Assessment of a Failed Test," May 4-7, 2009. 20 th AIAA Aerodynamic Decelerator Systems Technology Conference and Seminar, Seattle, Washington, AIAA paper 2009-2902.

${ }^{4}$ Cuthbert, P.A. and Conley, G.L., “A Desktop Application to Simulate Cargo Drop Tests," 23- 26 May,2005. 18 ${ }^{\text {th }}$ AIAA Aerodynamic Decelerator Systems Technology Conference and Seminar, Munich, Germany, AIAA paper 2005-1623.

${ }^{5}$ Fraire, U. J., Anderson, K., and Cuthbert, P. A., "Extraction and Separation Modeling of Orion Test Vehicles with ADAMS Simulation," $22^{\text {nd }}$ AIAA Aerodynamics Decelerator Systems Technology Conference, Daytona Beach, Florida, March 2013, AIAA paper 2013-1394.

${ }^{6}$ Haak, E. L. and Hovland, R. V., "Calculated Values of Transient and Steady State Performance Characteristics of Man-Carrying, Cargo, and Extraction Parachutes,” AFFDL-TR-66-103, Wright-Patterson Air Force Base, Ohio, November 1966, Air Force Systems Command.

${ }^{7}$ Ray, E. S., and Morris, A. L., "Challenges of CPAS Flight Testing," $21^{\text {st }}$ AIAA Aerodynamics Decelerator Systems Technology Conference, Dublin, Ireland, May 2011, AIAA paper 2011-2557.

${ }^{8}$ Moore, J. W., and Morris, A. L., "Development of Monte Carlo Capability for Orion Parachute Simulations," $21^{s t}$ AIAA Aerodynamics Decelerator Systems Technology Conference, Dublin, Ireland, May 2011, AIAA paper 2011-2610.

${ }^{9}$ Ray, E. S., "CPAS Simulation of Drop Test Vehicles and Test Techniques Version 13," JETS-JE11-13-SAIP-MEMO-0021, JSC Engineering Technology and Science contract, Jacobs Engineering, June 2014.

${ }^{10}$ NovAtel, Inc., "SPAN-SE," NovAtel, Inc. web site [online], February 2010, URL: http://novatel.com/Documents/Papers/SPANSE.pdf [cited 23 March 2010].

11 NovAtel, Inc., "IMU-HG," NovAtel, Inc. web site [online], 2009, URL: http://www.novatel.com/assets/Documents/Papers/HG1700_SPAN58.pdf [cited 18 August 2010].

${ }^{12}$ Lopez, M. A., Welch, M. J., and Yeary, W. H., "Evaluation of C-17A Aircraft Heavy Equipment Airdrop Capabilities," AFFTCTR-94-27, Air Force Flight Test Center Edwards Air Force Base, California, May 1995, Air Force Materiel Command.

${ }^{13}$ Peterson, D. and Roland, S., "Extraction Parachute Tow Testing Report," 93-470, Santa Anna, California, September 2012, Airborne Systems North America.

${ }^{14}$ Schulte, P. Z., Moore, J. W., and Morris, A. L., "Verification and Validation of Requirements on the CEV Parachute Assembly System Using Design of Experiments," $21^{\text {st }}$ AIAA Aerodynamics Decelerator Systems Technology Conference, Dublin, Ireland, May 2011, AIAA paper 2011-2558.

${ }^{15}$ Ray, E. S., "Reconstruction of Orion EDU Parachute Inflation Loads," 22 ${ }^{\text {nd }}$ AIAA Aerodynamics Decelerator Systems Technology Conference, Daytona Beach, Florida, March 2013, AIAA paper 2013-1260.

${ }^{16}$ Goscinski, J., “Ares I First Stage Drogue Drop Test Two (DDT-2) Data Analysis Report,” EA-CLV-TR-00785-2009, Bringham City, Utah, 5 November 2009, ATK Launch Systems, Inc.

${ }^{17}$ NASA Science News, "Ares Super-Chute [online]," 2009, URL: http://science.nasa.gov/science-news/science-atnasa/2009/13mar_superchute/

${ }^{18}$ Schmidt, J. R., et al., “Ares Main Parachute Overload Drop Test (MDT-4) Test Report,” EA-CLV-TR-01272-2011, Bringham City, Utah, 22 November 2011, ATK Launch Systems, Inc.

${ }^{19}$ Romero, L. M. and Ray, E. S., "Application of Statistically Derived CPAS Parachute Parameters," $22^{\text {nd }}$ AIAA Aerodynamics Decelerator Systems Technology Conference, Daytona Beach, Florida, March 2013, AIAA paper 2013-1266.

${ }^{20}$ Goscinski, J., “Ares I Main Parachute Drop Test \#3 Test Report,” EA-CLV-TR-00872-2009, Bringham City, Utah, 5 February 2010, ATK Launch Systems, Inc.

${ }^{21}$ Roland, S., "Air Launch Targets Extraction System: Extraction/Deployment Line Dynamics, EFTC Standard/Non-Standard," presented to the CPAS Hardware IPT on 10 September, 2013, Airborne Systems.

American Institute of Aeronautics and Astronautics 